\title{
When landscape variables do not explain migration rates: An example from an endangered dragonfly, Leucorrhinia caudalis (Odonata: Libellulidae)
}

\author{
JANINE BOLLIGER, DANIELA KELLER and RoLF HOLDEREGGER
}

Swiss Federal Research Institute WSL, Zürcherstrasse 111, CH-8903 Birmensdorf, Switzerland; e-mail: janine.bolliger@wsl.ch

Key words. Odonata, Leucorrhinia caudalis, assignment test, BIMR, contemporary gene flow, landscape genetics, microsatellites, Switzerland

\begin{abstract}
Leucorrhinia caudalis is a dragonfly species threatened throughout Europe. Despite evidence of the recent extension of its distribution range, it is unknown whether $L$. caudalis regularly or hardly ever migrates among ponds. The contemporary migration patterns of the species were investigated using Bayesian assignment tests and the migration rates related to landscape structural and thematic variables (distance between ponds, forest area, area of water body, area of hedgerow). Migration rates of $L$. caudalis are independent of any landscape element. Thus, landscape structure is not a barrier or corridor for migration in this species. The tendency of $L$. caudalis to disperse is largely independent of the nature of the landscape, at least at the scale of the present study.
\end{abstract}

\section{INTRODUCTION}

Migration patterns determine the dynamics of populations (Dieckmann et al., 1999), and their implications for demography and evolution are key research topics (Neilson et al., 2005; Berkley et al., 2010; Guichard et al., 2010). Landscape structure is a major determinant of movement in many organisms (Van Dyck \& Matthysen, 1999; Cushman, 2006; Marini et al., 2009; Romero et al., 2009), particularly in fragmented habitats (Watts et al., 2004; but see Diekötter et al., 2010). For wetlands in Europe, fragmentation of this inherently patchy habitat is ongoing due to continued land-use change such as intensification of agriculture or extension of settlements. Thus, a decline in the migration of specialist species among wetlands with negative consequence for population demography may be expected.

Here, the recent migration rates of the dragonfly Leucorrhinia caudalis (Charpentier, 1840) and the relationship of these rates to a set of thematic and structural landscape features is genetically assessed. Genetic methods are a promising alternative to observational studies on animal movement as they can be used to efficiently address migration at the landscape scale (Watts, 2009; Diekötter et al., 2010).

Leucorrhinia caudalis is a dragonfly threatened throughout its European distribution (Sternberg et al., 2000), including Switzerland (Vonwil \& Osterwalder, 2006). In 1980, only a single population survived in the Reuss Valley (Vonwil, 2005). However, in the 1990s and 2000s, new colonizations of ponds were recorded at distances between $500 \mathrm{~m}$ and $7 \mathrm{~km}$ from the probable source population. While these colonization events clearly show that dispersal occurs in L. caudalis, it is unknown whether migration among ponds occurs on a regular basis. The current populations of $L$. caudalis are characterized by substantial genetic variation (Keller et al., 2010), but this variation has not been used to study the influence of landscape elements on the movement of $L$. caudalis. For the damselfly Coenagrion mercuriale, however, it is known that its continuous stream habitat influences movement positively, whereas scrub boundaries and tall vegetation have a negative influence on movement (Purse et al., 2003).

The thematic and structural landscape features that are considered important in determining L. caudalis migration rates include distance between ponds, hedges as leading structures, forests as potential barriers and preference for various types of water bodies. These landscape features have been related to contemporary migration rates based on Bayesian assignment tests in a general linear modelling framework (Faubet et al., 2007; Faubet \& Gaggiotti, 2008). The present approach relates migration rates to landscape genetics, an emerging research field that combines theory and techniques of population genetics with the spatially dynamic framework of landscape ecology (Manel et al., 2003; Holderegger \& Wagner, 2008).

\section{MATERIAL AND METHODS}

The study species, L. caudalis, is a spring dragonfly emerging at the beginning of May. Its main flight season is between mid-May and mid-June (Vonwil, 2005). Populations of L. caudalis have been declining across its whole distribution range and many of the remaining populations are spatially isolated. Early in the 20th century, the species was widespread in the Swiss lowlands, but then suffered a substantial population decline in the late 20th century. Recently there has been an increase in the abundance and distribution of L. caudalis in Switzerland, although the species is generally considered a weak flier (Vonwil, 2005). No specific information is available on this species' flying habit.

An area of approximately $36 \mathrm{~km}^{2}$ located in the Reuss river Valley, Canton of Aargau, Switzerland (Fig. 1) was included in this study. The area is characterized by riparian areas, wetlands, intensive agriculture, settlement, and forest. Within this area, four ponds harboured larger populations (= 100 individuals) of L. caudalis in 2008 that were all sampled for this study (Fig. 1).

A non-invasive genetic sampling strategy was chosen: DNA was extracted from exuviae (Watts et al., 2005) or dead imagines from all the larger populations of $L$. caudalis in the Reuss Valley (FM, SRB, BW, UW; Table 1). A total of 113 samples (Table 1) were extracted and six microsatellite loci (Leucau03, Leucau04, Leucau06, Leucau10, Leucau15, and Leucau20) analysed using the procedures described in Keller et al. (2009). The extracted DNA was amplified many times and neither deviation from Hardy-Weinberg equilibrium nor linkage equilibrium was detected in the dataset. The genetic data used, the number of alleles detected and heterozygosity estimates, are also described in Keller et al. (2010). 


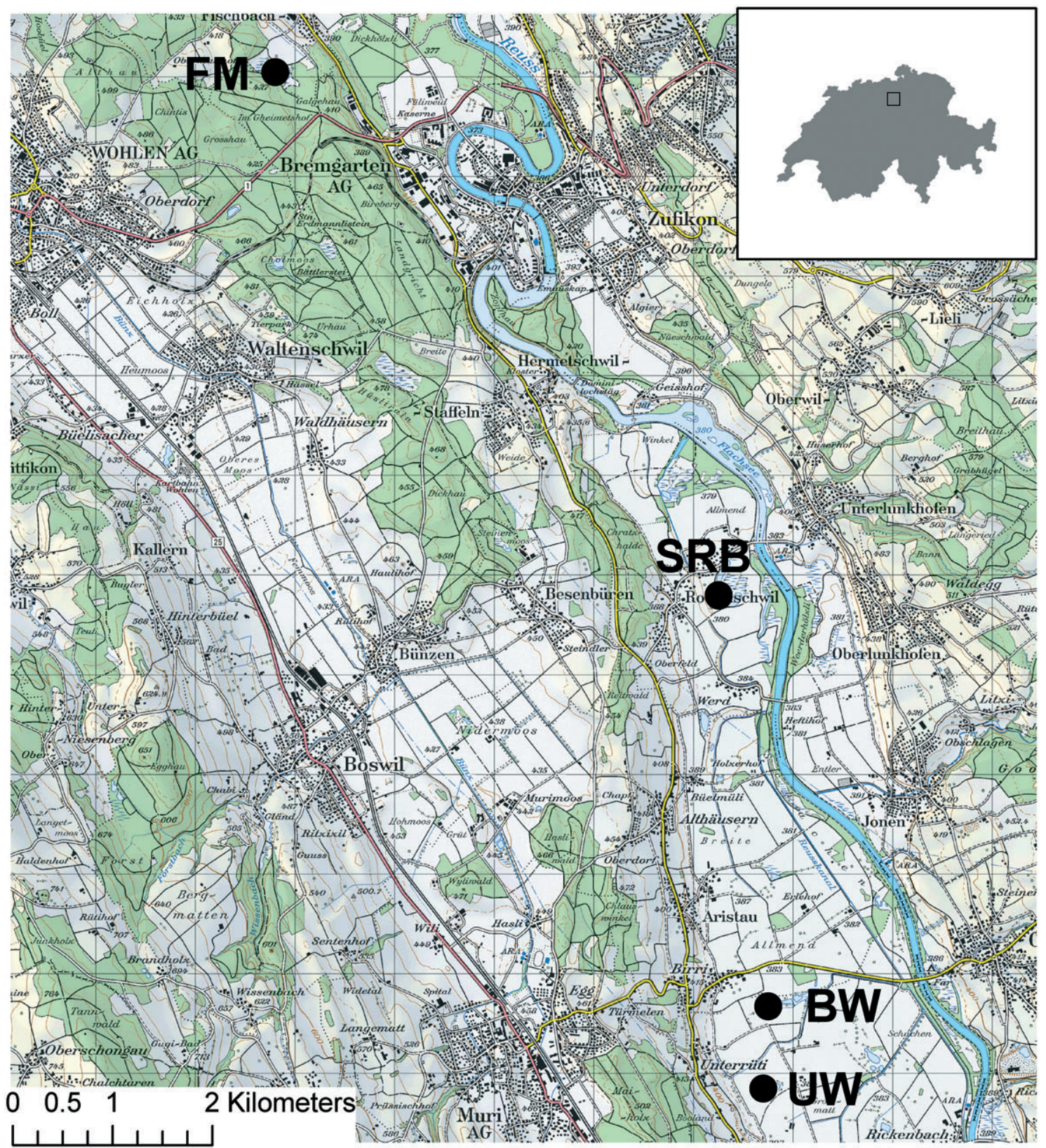

Fig. 1. Study area in the Reuss river valley in Switzerland (see the inlet) and location of the four populations of Leucorrhinia caudalis studied. For population abbreviations see Table 1.

The following landscape structural variables were considered as potentially important in determining dragonfly migration rates: (1) hedgerows, (2) water bodies, (3), forests, and (4) geographic distance between sampling sites. Information on land cover (forest, water bodies, hedgerows) was derived from vector25 data (Swisstopo). For each of these land-cover variables, length $(\mathrm{m})$ and area $\left(\mathrm{m}^{2}\right)$ of water bodies, forest area $\left(\mathrm{m}^{2}\right)$, and length $(\mathrm{m})$ and area $\left(\mathrm{m}^{2}\right)$ of hedgerows were calculated within straight-line corridors of different widths $(200,300,600 \mathrm{~m})$ between two ponds. However, as buffer sizes did not influence the results of the analysis, the present results are only for a width of $600 \mathrm{~m}$.

The spatial contiguity of the individual land-cover variables were addressed by using buffers. Hedgerows were buffered with $2 \mathrm{~m}$ and forest areas with $5 \mathrm{~m}$, water bodies were summed up over areas of lakes (buffered with $5 \mathrm{~m}$ ), rivers (buffered with 3 $\mathrm{m})$, and creeks (buffered with $1 \mathrm{~m}$ ). Euclidean distances (m) between ponds were chosen to address the effect of geographic distance between sites (i.e., isolation by distance; Wright, 1943).

These land-cover variables were then related to contemporary migration rates $(\mathrm{m})$ based on the Bayesian assignment test implemented in BIMR (Faubet et al., 2007; Faubet \& Gaggiotti, 2008). BIMR defines posterior estimates of last generation migration rates using Markov Chain Monte Carlo (MCMC) and Reversible Jump MCMC methods (Faubet et al., 2007; Faubet \& Giaggotti, 2008). Migration rates were related to land-cover variables based in a generalized linear model (GLM). The pairwise correlation between land-cover variables entering the GLM was maximally 0.6 .

BIMR runs to obtain migration rates and regression parameters were specified as follows. Several burnins between 10,000 and several millions were tested, but had no effect on the gen- 
TABLE 1. Abbreviations, location, altitude, census population size in 2008, and genetic sample size of the four populations of Leucorrhinia caudalis investigated in Switzerland.

\begin{tabular}{lccccc}
\hline Location & Abbreviation & Coordinates & Altitude (m a.s.l) & Census population size & Genetic sample size \\
\hline Fischbachermoos & FM & $665800 / 246050$ & 400 & 100 & 4 \\
Stille Reuss & SRB & $670250 / 240800$ & 380 & 9000 & 48 \\
Birriweiher & BW & $670750 / 236675$ & 380 & 600 & 30 \\
Unterrütiweiher & UW & $670700 / 235850$ & 380 & 800 & 31 \\
\hline
\end{tabular}

eral pattern of the migration rates. Thus, a burnin period of 20,000 runs, a sample size of 20,000 runs and ten replicates per run, were chosen. Priors of the migration rates were varied between $10-100 \%$ at $10 \%$ intervals to identify the relative effects of priors on the migration rate determined from the genetic data set. Mean and standard deviations for posterior regression model probabilities of the ten replicates per run were calculated for all land-cover variables individually. BIMR can handle sample sets as low as $n=3$ per population (Faubet \& Giaggiotti, 2008), therefore, the results for all four ponds sampled were included in the analysis. Because lengths of water bodies and hedgerows did not explain more variation in the genetic data set than did the area covered by these land-cover variables, the final full model only contained the variables areas of forest, water bodies, and hedgerows as well as geographic distance.

\section{RESULTS AND DISCUSSION}

Microsatellites in dragon- and damselflies have been used to assess (neutral) genetic diversity (Watts et al., 2006), genetic differences among consecutive generations (Lowe, 2009), contemporary migration rates (Watts et al., 2007a), effective population sizes (Watts et al., 2007b), and isolation-by-distance based on genetic differentiation (Watts et al., 2004). In this study, the application of microsatellites was extended to dragonflies and damselflies in order to better understand the relationship between contemporary migration rates of $L$. caudalis and thematic and structural landscape features.

However, the effectiveness of this approach may be limited if the sample size is small. As only four ponds were sampled, it is possible that the statistical power was low to accurately describe recent migration patterns and detect any landscape influences on these patterns. Furthermore, the six loci used may not have been sufficient to accurately describe genetic migration rates among the ponds sampled. In addition, the landscape elements recorded are not equally distributed across the landscape. Thus, the effect of less frequent landscape elements (e.g., forests) may have been underestimated. Finally, the results reported in this paper only refer to the spatial scale and landscape investigated. Whether these results may be transferred to other landscapes and scales remains to be tested (e.g., by providing landscape replicates).

Different priors for the proporiton of migrating individuals $(10-100 \%)$ in BIMR did not strongly influence the estimation of the overall migration rates (Fig. 2). Figure 2, however, shows the distinct directionality of the migration rates for population FM. This population (Table 1) was exclusively a sink for migrants. In contrast, migration rates among populations SRB, BW, and UW had no obvious differences in directionality, thus they interacted in a similar way (all showing migration rates of about 0.2 ; Fig. 2). The observed migration rates were independent of any landscape structural or thematic feature as the migration rates across the landscape were similar (Table 2). This lack of landscape effects on migration rates accord with other published studies on dragon- and damselflies, which indicate no significant genetic differences at distances of up to $8 \mathrm{~km}$ (Wong et al., 2003; but see Purse et al., 2003). The implication for practical conservation is that landscape structure does not constitute a barrier or obvious leading structures that hinder or facilitate the migration of $L$. caudalis. Long distance flights of this dragonfly are probably not affected by landscape structure, at least at the scale of the present study.

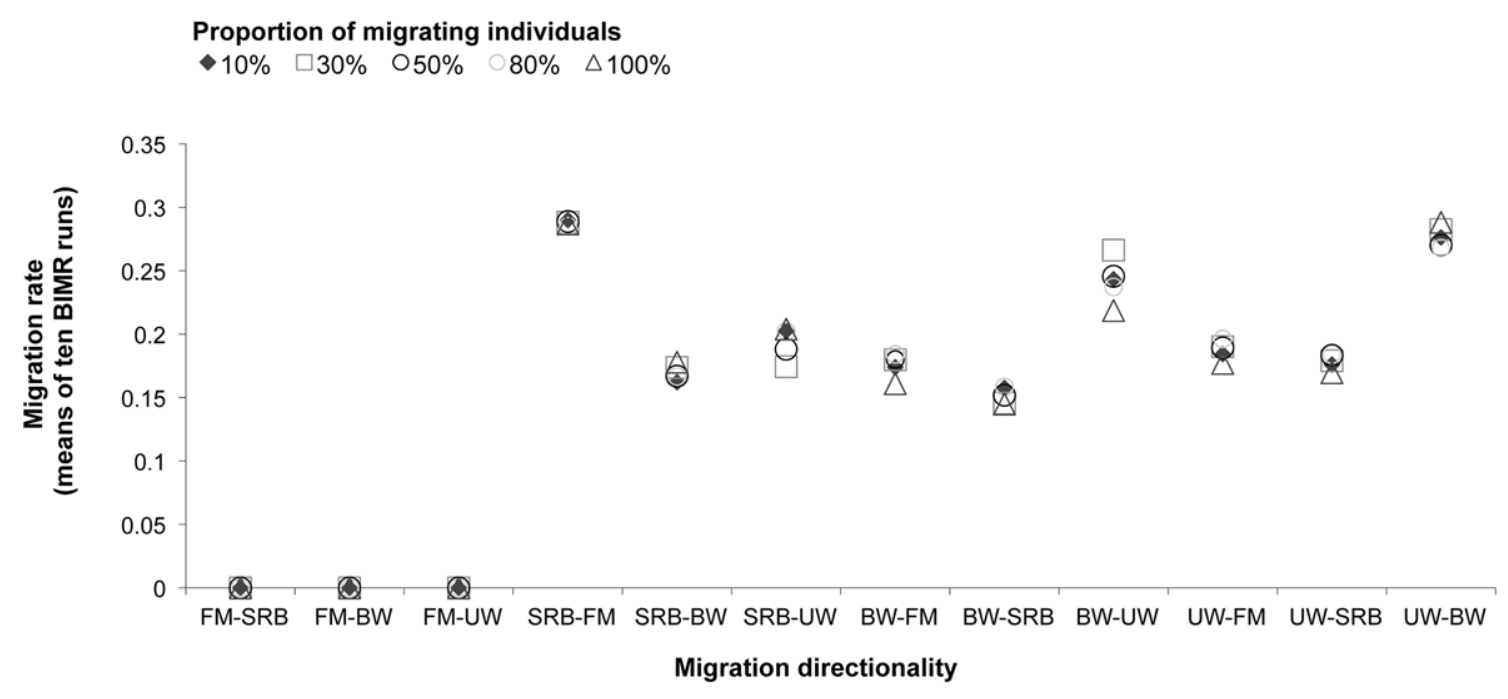

Fig. 2. Examples of the influence of different priors of migration rates on means of the estimated migration rates and migration directionality for ten BIMR runs (Faubet et al., 2007; Faubet \& Gaggiotti, 2008) of the landscape genetic analysis of Leucorrhinia caudalis. For population abbreviations see Table 1. The pond listed first is the source of migrants, while the second pond is the sink. 
TABLE 2. Mean and standard deviation of posterior probabilities derived from runs of ten BIMR regression models (Faubet et al., 2007; Faubet \& Gaggiotti, 2008) that included different land-cover variables. G1: Euclidean distance (m); G2: forest area $\left(\mathrm{m}_{-}^{2}\right)$; G3: water body area $\left(\mathrm{m}^{2}\right)$; G4: hedgerow area $\left(\mathrm{m}^{2}\right)$. The posterior probability is the conditional probability that is assigned after land-cover variables are taken into account.

\begin{tabular}{lcc}
\hline \multirow{2}{*}{ Land-cover variables } & \multicolumn{2}{c}{ Posterior probabilities } \\
& Mean & Standard deviation \\
\hline None & 20.33 & 3.30 \\
G1 & 5.92 & 0.51 \\
G2 & 5.81 & 0.84 \\
G1 G2 & 2.28 & 0.16 \\
G3 & 5.84 & 0.89 \\
G1 G3 & 1.68 & 0.17 \\
G2 G3 & 2.12 & 0.22 \\
G1 G2 G3 & 0.81 & 0.08 \\
G4 & 5.57 & 0.69 \\
G1 G4 & 1.84 & 0.15 \\
G2 G4 & 1.80 & 0.19 \\
G1 G2 G4 & 1.00 & 0.08 \\
G3 G4 & 2.47 & 0.18 \\
G1 G3 G4 & 1.11 & 0.08 \\
G2 G3 G4 & 0.99 & 0.10 \\
G1 G2 G3 G4 & 0.60 & 0.07 \\
\hline
\end{tabular}

ACKNOWLEDGEMENTS. We would like to thank the Canton of Aargau, Switzerland, for permission to work with L. caudalis and for financial support.

\section{REFERENCES}

Berkley H.A., Kendall B.E., Mitarai S. \& Siegel D.A. 2010: Turbulent dispersal promotes species coexistence. Ecol. Letters 13: 360-371.

Cushman S.A. 2006: Effects of habitat loss and fragmentation on amphibians: a review and prospects. Biol. Conserv. 128: 231-240.

Dieckmann U., O'Hara B. \& Weisser W. 1999: The evolutionary ecology of dispersal. Trends Ecol. Evol. 14: 88-90.

Diekötter T., Baveco H., Arens P., Rothenbuhler C., Billeter R., Csencsics D., De Filippi R., Hendrickx F., Speelmans M., Opdam P. \& Smulders M.J.M. 2010: Patterns of habitat occupancy, genetic variation and predicted movement of a flightless bush cricket, Pholidoptera griseoaptera, in an agricultural mosaic landscape. Landsc. Ecol. 25: 449-461.

Faubet P. \& GagGiotti O.E. 2008: A new Bayesian method to identify the environmental factors that influence recent migration. Genetics 178: 1491-1504.

Faubet P., Waples R.S. \& Gaggiotti O.E. 2007: Evaluating the performance of a multilocus Bayesian method for the estimation of migration rates. Mol. Ecol. 16: 1149-1166.

Guichard S., Kriticos D.J., Leriche A., Worner S.P., Kean J.M. \& SuckLING D.M. 2010: Evidence of active or passive downwind dispersal in mark-release-recapture of moths. Entomol. Exp. Appl. 134: 160-169.

HOLDEREGGer R. \& WAGNER H.H. 2008: Landscape genetics. BioScience 58: 199-207.

Keller D., Brodbeck S. \& Holderegger R. 2009: Characterization of microsatellite loci in Leucorrhinia caudalis, a rare dragonfly endangered throughout Europe. Conserv. Genet. Resour. 1: 179-181.

Keller D., Brodbeck S., Flöss I., Vonwil G. \& Holderegger R. 2010: Ecological and genetic measurements of dispersal in a threatened dragonfly. Biol. Conserv. 143: 2658-2663.
Lowe W.H. 2009: What drives long-distance dispersal? A test of theoretical predictions. Ecology 90: 1456-1462.

Manel S., Schwartz M., Luikart G. \& Taberlet P. 2003: Landscape genetics: combining landscape ecology and population genetics. Trends Ecol. Evol. 18: 189-197.

Marini L., Fontana P., Battisti A. \& Gaston K.J. 2009: Agricultural management, vegetation traits and landscape drive orthopteran and butterfly diversity in a grassland-forest mosaic: a multi-scale approach. Insect Conserv. Divers. 2: 213-220.

Neilson R.P., Pitelka L.F., Solomon A.M., Nathan R., Midgley G.F., Fragoso J.M.V., LischKe H. \& Thompson K. 2005: Forecasting regional to global plant migration in response to climate change. BioScience 55: 749-759.

Purse B.V., Hopkins G.W., Day K.J. \& Thompson D.J. 2003: Dispersal characteristics and management of a rare damselfly. J. Appl. Ecol. 40: 716-728.

Romero S., Campbell J.F., Nechols J.R. \& With K.A. 2009: Movement behavior in response to landscape structure: the role of functional grain. Landsc. Ecol. 24: 39-51.

Sternberg K., Höppner K., Schiel F.-J. \& Rademacher M. 2000: Leucorrhinia caudalis (Charpentier, 1840). In Sternberg K. \& Buchwald R. (eds): Die Libellen Baden Württembergs. Ulmer, Stuttgart, pp. 294-297.

Swisstopo. Vektor 25. Bundesamt für Landestopographie, Wabern.

VAn Dyck H. \& Matthysen E. 1999: Habitat fragmentation and insect flight: a changing "design" in a changing landscape? Trends Ecol. Evol. 14: 172-174.

VonwIL G. 2005: Leucorrhinia caudalis (Charpentier 1840). In Wildermuth H., Gonseth Y. \& Maibach A. (eds): OdonataLibellen der Schweiz. CSCF/SEG, Neuchâtel, pp. 294-297.

Vonwil G. \& Osterwalder R. 2006: Kontrollprogramm Natur und Landschaft. Die Libellen im Kanton Aargau. Umwelt Aargau 23: 13-45.

WatTs P.C. 2009: Characteristics o microsatellite loci in Odonata. Int. J. Odonatol. 12: 275-286.

Watts P.C., Rouquette J.R., SAccheri J., Kemp S.J. \& Thompson D.J. 2004: Molecular and ecological evidence for small-scale isolation by distance in an endangered damselfly, Coenagrion mercuriale. Mol. Ecol. 13: 2931-2945.

Watts P.C., Thompson D.J., Daguet C. \& Kemp S.J. 2005: Exuviae as reliable source of DNA for population-genetic analysis of odonates. Odonatologica 34: 183-187.

WatTS P.C., SACCheri I.J., KemP S.J. \& Thompson D.J. 2006: Population structure and the impact of regional and local habitat isolation upon levels of genetic diversity of the endangered damselfly Coenagrion mercuriale (Odonata: Zygoptera). Freshw. Biol. 51: 193-205.

Watts P.C., Rousset F., SAccheri I.J., Leblois R., Kemp S.J. \& Thоmpson D.J. 2007a: Compatible genetic and ecological estimates of dispersal rates in insect (Coenagrion mercuriale: Odonata: Zygoptera) populations: analysis of "neighbourhood size" using a more precise estimator. Mol. Ecol. 16: 737-751.

Watts P.C., SAccheri I.J., Kemp S.J. \& Thompson D.J. 2007b: Effective population sizes and migration rates in fragmented populations of an endangered insect (Coenagrion mercuriale: Odonata). J. Anim. Ecol. 76: 790-800.

Wong A., Sмith M.L. \& Forbes M.R. 2003: Differentiation between subpopulations of a polychromatic damselfly with respect to morph frequencies, but not neutral genetic markers. Mol. Ecol. 12: 3505-3513.

WRIGHT S. 1943: Isolation by distance. Genetics 28: 114-138.

Received September 16, 2010; revised and accepted December 15, 2010 